Original Research Paper

\title{
Assessment of Genetic Purity of Parental Lines of Hybrid Rice Using DNA-Based Markers
}

\author{
${ }^{1}$ Sunil Bhavsar, ${ }^{1}$ Twinkle Solanki, ${ }^{1}$ Suchita Amin and ${ }^{2}$ Neeru Jain \\ ${ }^{I}$ Department of Biotechnology, Veer Narmad South Gujarat University, Surat, Gujarat, India \\ ${ }^{2}$ Barwale knowledge and Study Centre, Barwale Foundation, Jalna, Maharashtra, India
}

\author{
Article history \\ Received: 22-03-2015 \\ Revised: 01-06-2015 \\ Accepted: 08-06-2015 \\ Corresponding Author: \\ Sunil Bhavsar \\ Department of Biotechnology, \\ Veer Narmad South Gujarat \\ University, Surat, Gujarat, \\ India \\ Email: ssunil48@gmail.com
}

\begin{abstract}
Assessment of hybrid seed genetic purity is one of the most important quality control parameters in hybrid seed production. With the objective of replacing the GOT with DNA based assays, Cytoplasmic Male Sterile (CMS), restorer and hybrid lines have been screened by means of microsatellite and Sequence Tagged Site (STS) markers. Cytoplasmic Male Sterile (CMS) lines often get contaminated with cognate isonuclear maintainer lines during multiplication. The PCR assay was able to detect precisely the impurities in a commercial seed lot of CMS line. The extent of heterozygosity within parental lines of rice hybrids were assessed and the results suggest that a single, appropriately chosen microsatellite marker should be sufficient for assessing hybrid seed purity.
\end{abstract}

Keywords: Hybrid Seed, Cytoplasmic Male Sterile, PCR, Heterozygosity

\section{Introduction}

Rice, Oryza sativa L. is the most important staple crop feeding over half of the world population. The present world population of about 6 billion is likely to cross 8 billion by the year 2030, which necessitates that rice production must increase by $40 \%$ to keep pace with the increasing trend in the population growth. Hybrid rice is one of the technological options that will impact the world's rice production (Khush, 2005). Hybrid rice technology appears to be a feasible and readily available option for raising yield potential. In China, about $50 \%$ of land under rice cultivation is occupied by hybrid rice, thus making it the largest producer of hybrid rice (Jirong, 2000). Besides, China, hybrid rice is successfully grown in countries like India, Vietnam, Philippines, Latin American countries, to a small extent only. Though the area occupied by hybrid rice in India is still small but it is expected to increase substantially.

Availability of efficient male sterility systems is a prerequisite for the development of hybrids in rice. Mainly, three types of male sterility systems: Genetic Male Sterility (GMS), Cytoplasmic Male Sterility (CMS) and Environment-Sensitive Genetic Male Sterility (EGMS) are well recognized in rice. Of these, the CMS system has been the most effective for hybrid rice breeding. Till date, more than 40 different CMS sources have been reported in rice (Virmani and Shinjyo, 1988). The discovery of a male-sterility inducing cytoplasm designated „Wild Abortive" (WA) cytoplasm from a wild rice. The CMS based hybrid breeding system involving male sterile (CMS/A), maintainer (CMS/B) and Restorer (R) lines is popularly known as three line breeding (Virmani, 1993). Currently, two different technologies are adopted for the development of rice hybrids. One is the "three-line system" involving a CMS line, maintainer line and restorer line. The other system is the "two-line system" wherein only two lines (designated as male and female) are involved in the hybrid seed production. Among the CMS lines used for development of three- line rice hybrids, lines based on WA cytoplasm originally derived from a wild rice are the most popular in all countries where hybrid rice is cultivated on a commercial scale (Yuan, 1995).

Essentially, in the CMS lines certain genes are present in the mitochondria, which are responsible for cellular respiration. If these genes are absent or their function is hampered, the mitochondria becomes nonfunctional as a result of which the viable microspores are not produced as mitochondria follows maternal inheritance Gallagher et al., 2002, Satoh et al., 2004, Yamamoto et al., 2005, Wang et al., 2006). In a selfpollinated crop like rice, one of the challenges is the production and supply of adequate quantities of pure hybrid seed to the farmers. Maintenance of high level of genetic purity of hybrid is essential to exploit the 
moderate level of heterosis observed in this crop. The success of hybrid rice technology depends on efficient seed production techniques to ensure timely supply of genetically pure seeds. It has been reported that even $1 \%$ impurity in hybrid seed can lead to yield reduction of about $100 \mathrm{~kg}$ per ha at farmers' fields (Mao et al., 1996). Indian Seed Act (1966) recommends ensuring 98\% genetic purity in commercial hybrid seed lots (Sindhu and Kumar 2002). The required levels of hybrid seed purity can be ensured by using pure parental lines in hybrid seed production. The most commonly observed contamination in hybrid seed production is that of maintainer line getting admixed with CMS line (Yashitola et al., 2004).

For accurate detection of impurities in seed lots, it is essential to identify a set of informative SSR markers which can clearly distinguish the parental lines and amplify specific or unique allele combinations in the hybrids, not present in any other rice line. The fingerprinting of rice hybrids and identification of their genetic relationships are essential for plant improvement, variety registration system, DUS testing, seed genetic purity testing and the Protection of Plant Variety and Breeders "Rights. Accordingly, clear-cut identification of elite crop varieties and hybrids it is essential for protection and prevention of unauthorized commercial use (Nandakumar et al., 2004).

The present work had been undertaken to validate some known markers for discriminating cms lines with their isogenic counterparts, maintainer lines. All the markers employed during the study are PCR-based and are of different nature.

\section{Materials and Methods}

\section{Seed Material}

Five Cytoplasmic Male Sterile (CMS) lines, five maintainer lines and six restorer lines and two commercial hybrids based on WA cytoplasm were used in the present study (Table 1). The rice germplasms was obtained from Barwale Foundation, Research and Training Centre, Hyderabad. The material has been originally procured from the International Rice Research Institute (IRRI), Philippines.

\section{Seed Germination}

Seeds were placed on Petri plates lined with germination paper soaked with water. Petri plates were incubated at $25 \pm 2^{\circ} \mathrm{C}$, for 7-8 days. The papers were wetted with $1 \mathrm{ml}$ water, if required. 10-day-old seedlings were used for DNA extraction (Fig. 1).

\section{DNA Isolation}

Genomic DNA was extracted from four-week-old rice seedlings, using modified Dellaporta method (Dellaporta et al., 1983).

\section{Quantification of Genomic DNA}

The DNA yield per microgram of seed samples was measured by using a Bio photometer (Bio- Rad) at $260 \mathrm{~nm}$. DNA purity was determined by calculating the absorbance ratio A260/280. The DNA sample was also quantified on $1 \%$ agarose gel electrophoresis.

\section{PCR Amplification}

The PCR amplification was carried out in a total volume of $20 \mu \mathrm{L}$ and the cocktail was composed of $2.5 \mu \mathrm{L}$ of $10 \mathrm{X}$ PCR buffer, $2 \mu \mathrm{L}$ of $40 \mathrm{mM}$ of dNTP "s mix, $0.5 \mu \mathrm{L}$ of 25 $\mathrm{mM} \mathrm{MgCl} 2,1 \mu \mathrm{L}$ of $10 \mu \mathrm{M}$ Primer, $0.5 \mu \mathrm{L}$ Taq polymerase (3 units $\mu \mathrm{L}^{-1}$ ), $11.5 \mu \mathrm{L}$ of sterile distilled water, $2 \mu \mathrm{L}$ of genomic DNA $\left(10 \mathrm{ng} \mu \mathrm{L}^{-1}\right)$. The amplification was carried out in Eppendorf thermocycler. The amplification was carried out at the program comprising of initial denaturation at $94^{\circ} \mathrm{C}$ for $5 \mathrm{~min}$, followed by 35 cycles of cyclic denaturation at $94^{\circ} \mathrm{C}$ for $1 \mathrm{~min}$, annealing at $55^{\circ} \mathrm{C}$ for $1 \mathrm{~min}$, cyclic extension at $72^{\circ} \mathrm{C}$ for $1 \mathrm{~min}$ and finally an extension at $72^{\circ} \mathrm{C}$ for $5 \mathrm{~min}$. A total of 12 oligonucleotide primers were used for PCR amplification (Table 2). These primers were selected from the literature.

The amplified products were resolved on $1.5 \%$ agarose gels in $1 \mathrm{X}$ TAE buffer. The size of bands was estimated using a 100 base pair ladder. Bands were visualized under UV light in gel documentation systems and captured images were used for further analyses.

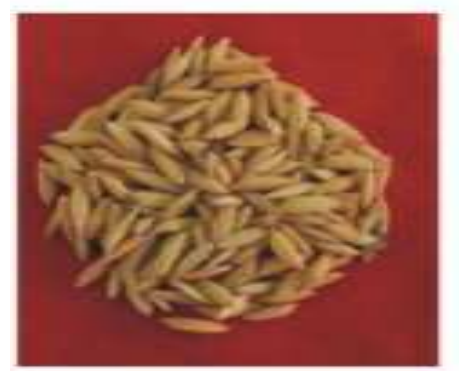

(A)

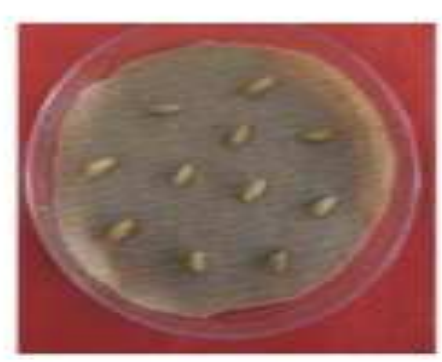

(B)

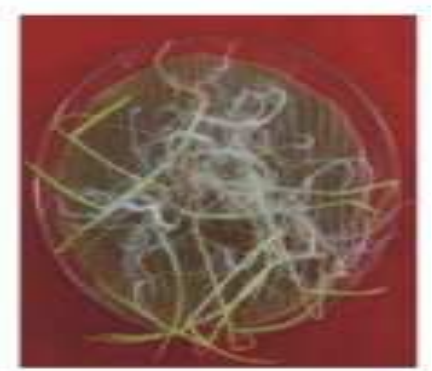

(C)

Fig. 1. Seed germination for DNA extraction (A) Seeds (B) Seeds kept for germination (C) 10-day-old seedling 


\begin{tabular}{|c|c|c|c|c|c|}
\hline Sr. no. & Type & Lines & Sr. no. & Type & Lines \\
\hline & & IR $58025 \mathrm{~A}$ & & & IR $58025 \mathrm{~B}$ \\
\hline & & IR $68888 \mathrm{~A}$ & & & IR 68888 B \\
\hline & & IR $68897 \mathrm{~A}$ & & & IR 68897 B \\
\hline \multirow[t]{4}{*}{1} & CMS line & IR $79128 \mathrm{~A}$ & 2 & Maintainer & IR 79128 B \\
\hline & & IR $79156 \mathrm{~A}$ & & & IR 79156 B \\
\hline & & IR 58103-62-3R & & & \\
\hline & & IR $62037-12-1-2-2-2 R$ & & & \\
\hline \multirow[t]{4}{*}{3} & Restorer & IR $65483-14-1-4-13 R$ & & & \\
\hline & & IR $68445-62-1-3-1 R$ & & & \\
\hline & & IR $7160-4-1-4-4-4-2-2-2 R$ & & & \\
\hline & & IR 72R & & & \\
\hline
\end{tabular}

Table 2: Details of primers used for amplification during present study

\begin{tabular}{|c|c|c|}
\hline Primer name & Sequence $\left(5^{`}-3^{`}\right)$ & References \\
\hline DRRCMS-Forward & $5^{`}$ - ACCTTTGGGCGATGGTT - 3` & (Rajendrakumar et al., 2007) \\
\hline DRRCMS-Reverse & 5` - GGGTTTAGAGTCGCCAC - 3 & \\
\hline CMS-Forward & $5^{`}$ - ACTTTTTGTTTT TGTGTAGG - 3` & (Yashitola et al., 2004) \\
\hline CMS-Reverse & $5 `$ - TGCCATATGTCGCTTAGACTTTAC - 3` & \\
\hline BFSTS401-Forward & $5^{`}$ - TGCCACTAT TCCACAATGCATG - 3` & (Rajendran et al., 2007) \\
\hline BFSTS401-Reverse & 5` - CССТТTCCTGCТТCССТTTTTTA - 3` & \\
\hline BFSTS402-Forward & $5 `$ - TAGGGCCATGACGGTTTTG - 3` & (Rajendran et al., 2007) \\
\hline BFSTS402-Reverse & 5` - CGCGTCCTTCCCCAATT - 3` & \\
\hline pTA248-Forward & 5` - AGACGCGGAAGGGTGGTTCCCGGA - 3` & (Yashitola et al., 2002) \\
\hline TA248-Reverse & $5 `$ - AGACCGGTAATCGAAAGATGAAAA -3’ & \\
\hline RMT6-Forward & 5` - GATGGTTTGGAAGGCTG - 3` & (Rajendrakumar et al., 2007) \\
\hline RMT6-Reverse & 5 - GGGTTTAGAGTCGCCA - 3 & \\
\hline
\end{tabular}

\section{Results and Discussion}

10-day-old seedling was used for DNA extraction. DNA was extracted from all the 18 lines of rice as listed in Table 1. About 10 preparations of each genotype were prepared in order to select the best preparation. Extracted DNA was analyzed using the Bio photometer and the quantity of DNA was assessed on the basis of readings recorded at 260 $\mathrm{nm}$, while the quality of DNA was checked on the basis of ratios of 230, 260 and $280 \mathrm{~nm}$.

PCR amplifications were carried out with six primer pairs (Table 2).

\section{Amplification Pattern Generated by CMS Primer Pair}

cms primer pair generated a band of 386 bp in CMS line which was absent in both the maintainer and restorer lines. During the present study, we had analyzed five different CMS lines. As reported in literature four CMS lines viz., IR 58025, IR 68897, IR 79128, IR 79156 generated a band of 386 bp in CMS lines, which was absent in their counter maintainer lines (Fig. 2 A, B and C). Likewise, this band was absent in the entire restorer lines tested (Fig. 2 D). In one CMS line (IR 68888) this band could not be detected even in the single individual genotype analyzed (Fig. 2 B). The lower band present in the gel is below a $100 \mathrm{bp}$ size and it is due to primer dimer so it is not considered during scoring of results. Using this primer, it was concluded that CMS lines have the band, but it is completely absent in maintainer lines as well as all restorer. However, all the individuals of CMS lines (IR 78128 A and IR 79156 A) show this band uniformly.

\section{Amplification Pattern Generated by DRRCMS Primer Pair}

drrcms amplified 130 bp in CMS line and 142 bp in maintainer line. All genotypes of IR 58025 A amplified a single band of $130 \mathrm{bp}$, while its cognate maintainer (IR 58025 B) amplified two bands one line CMS counterpart i.e., $130 \mathrm{bp}$ and an additional band of $142 \mathrm{bp}$ (Fig. 3 A). In IR 68888 A lines, out of five genotypes tested only in three individuals $130 \mathrm{bp}$ band was detected, while in other two individuals it was absent. In its maintainer line (IR $68888 \mathrm{~B}$ ), only three individuals developed two bands (130 bp and $142 \mathrm{bp}$ ), while in one genotype only $130 \mathrm{bp}$ appeared. In the fifth individual both bands failed to amplify (Fig. 3 B, C). IR 79128 A and IR 79156 A developed a banding pattern similar to the maintainer lines; hence this primer is not suitable for discriminating these two CMS lines from their maintainer (Fig. 3 C). In four restorer lines, four (R1, R2, R3 and R4) both bands (130 bp and $142 \mathrm{bp}$ ) developed, however, the intensity of 142 bp band was not very strong. The fifth restorer line (IR 72) did not amplify any of these bands (Fig. 3 D). 


\section{Amplification Pattern Generated by RMT 6 Primer Pair}

RMT 6 generated multiple bands in both CMS and their cognate maintainer lines. Such banding pattern was almost uniform for all five sets of CMS line pairs (Fig. 4 A-C). However, this primer pair could differentiate the restorer lines from CMS/maintainer lines as it failed to generate any banding pattern in any of the five selected lines (Fig. 4 D).

\section{Amplification Pattern Generated by BF-STS-402 Primer Pair}

BF-STS-402 generated a single band of $336 \mathrm{bp}$ in all the lines of tested. This band was uniformly present in all CMS lines along with their maintainers. Furthermore, this band was also present in all restorer lines (Fig. 5 A-D). This primers pair is not suitable for differentiating any combination of lines used in hybrid rice breeding programs.

\section{Amplification Pattern Generated by BF-STS-401 Primer Pair}

BF-STS-401 could differentiate CMS and its cognate maintainer lines. IR 58025 A and IR 58025 B exhibited a differential pattern of discriminating CMS and maintainer lines in comparison to other CMS pairs (Fig. 6 A). In IR $58025 \mathrm{~B}$ an additional band (1300 bp) was amplified in addition to a band of $469 \mathrm{bp}$ present in CMS line (IR 58025 A). For other four CMS lines, (IR68888 A, IR 6897 A, IR 79128 A and IR 79156 A) amplified a desired band of 409 bp uniformly, while it was completely absent in respective maintainers for all four cases (Fig. 6 B, C). Likewise, the band was completely absent from all five restorer lines too (Fig. 6 D). Therefore, this primer can be best suited for discriminating maintainers, restorers lines from CMS line.

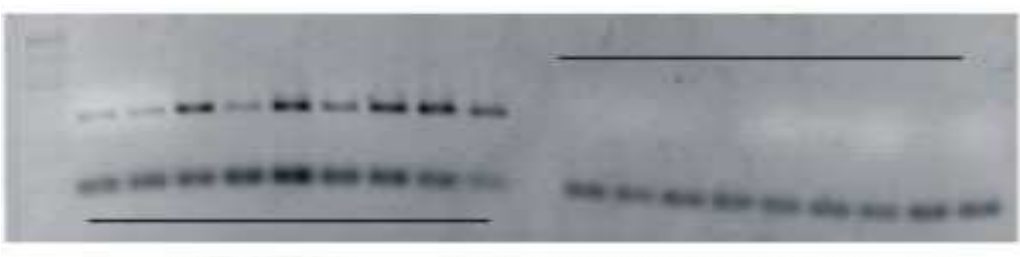

IR $58025 \mathrm{~A}$

IR. 58025 B

(A)

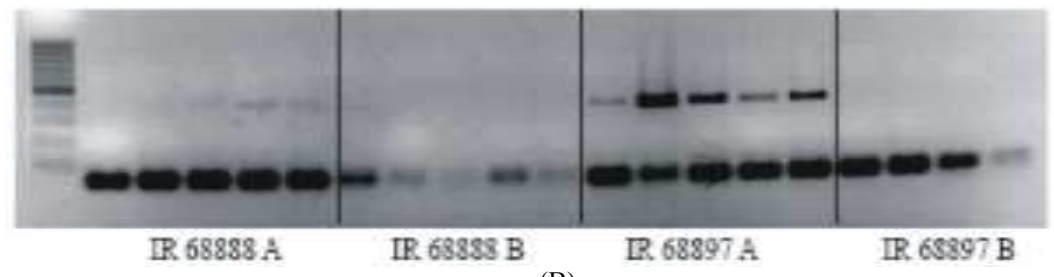

(B)
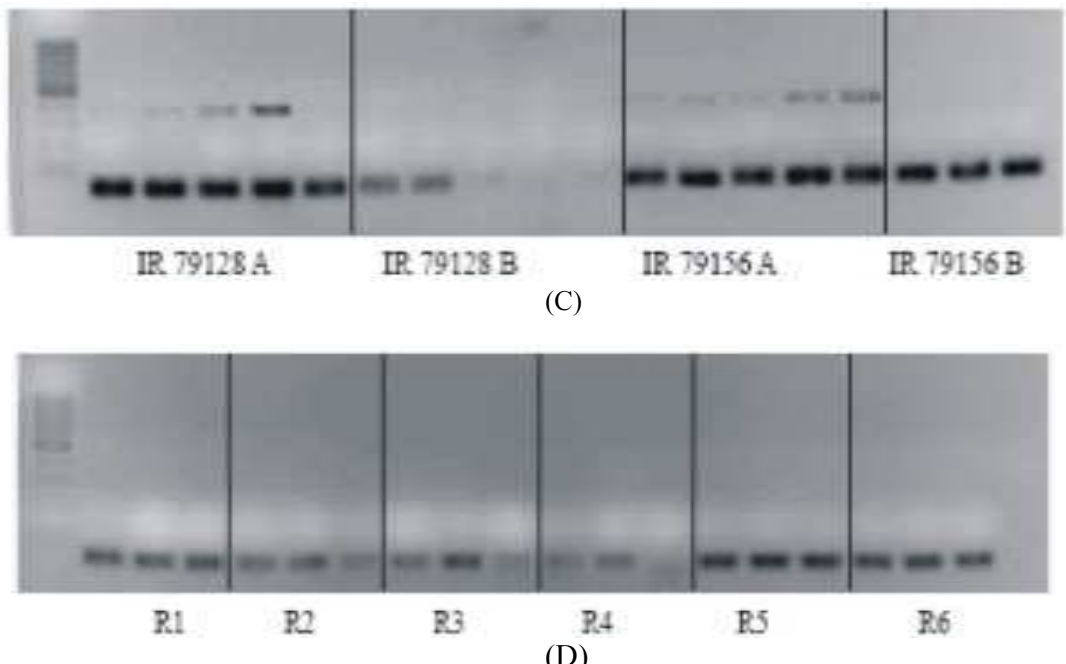

Fig. 2. Amplification profile of rice genotypes: CMS lines and their cognate maintainers, restorer lines, with cms primers 


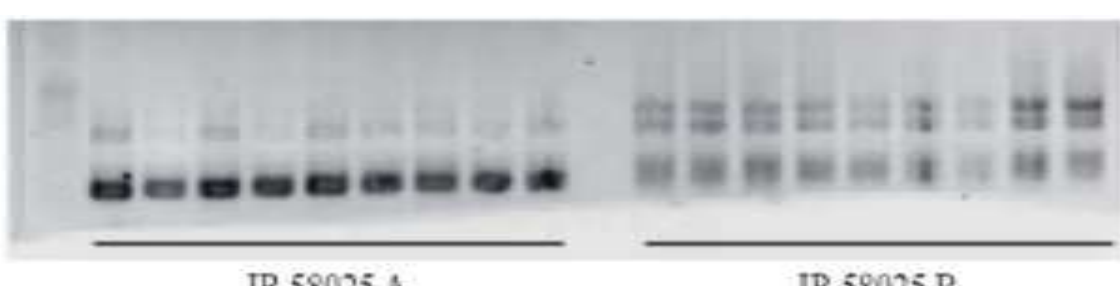

(A)

IR 58025 B

A)

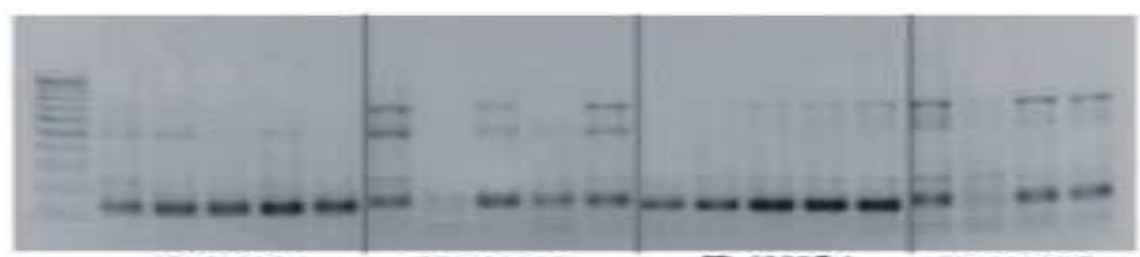

(B)

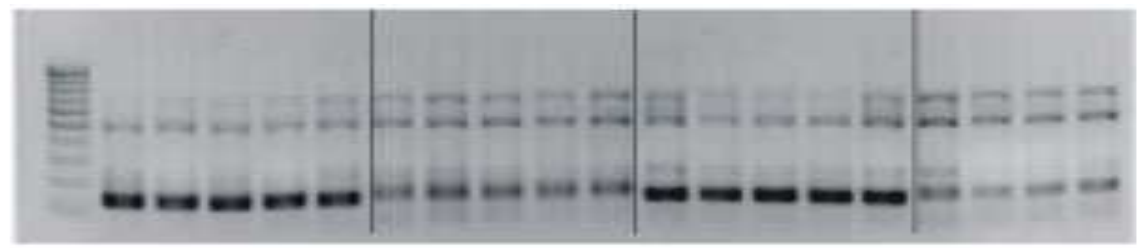

$\mathbb{I R} 79128 \mathrm{~A} \quad \mathbb{R} 79128 \mathrm{~B}$

(C)

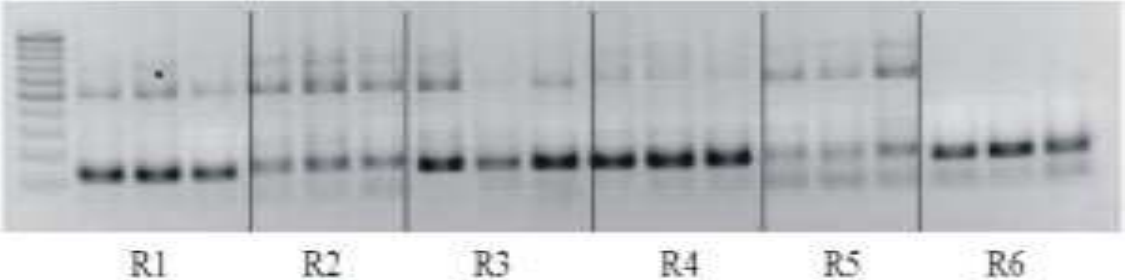

(D)

Fig. 3. Amplification profile of rice genotypes: CMS lines and their cognate maintainers, restorer lines, with drrcms primers

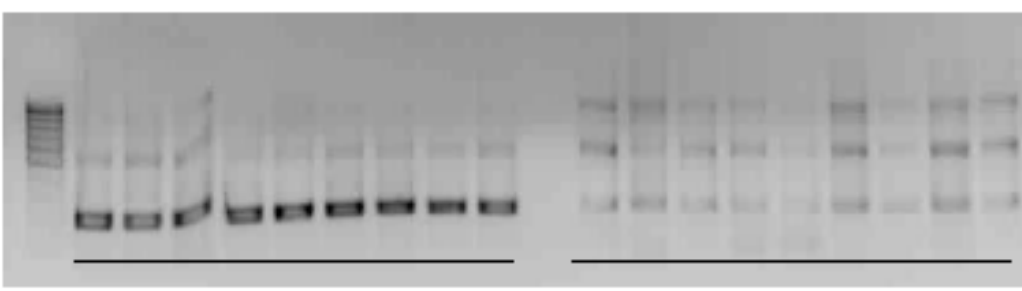

IR $58025 \mathrm{~A}$

IR $58025 \mathrm{~B}$

(A)

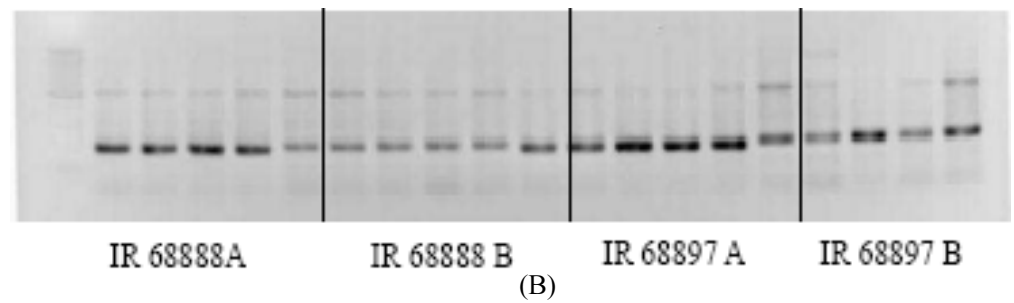




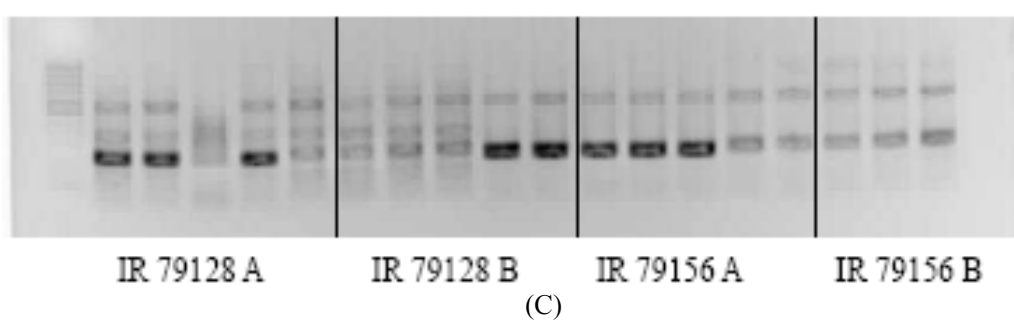

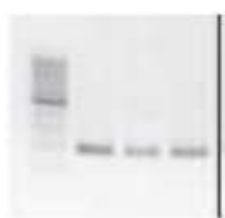

R.1

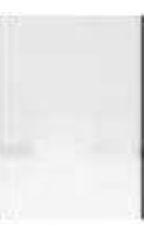

R2

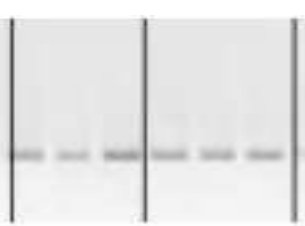

R3
R4

(D)

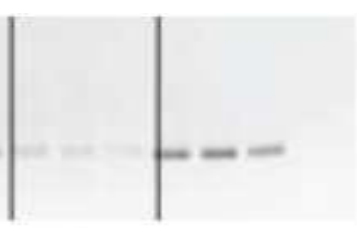

R5

R6

Fig. 4. Amplification profile of rice genotypes: CMS lines and their cognate maintainers, restorer lines, with RMT 6 primers

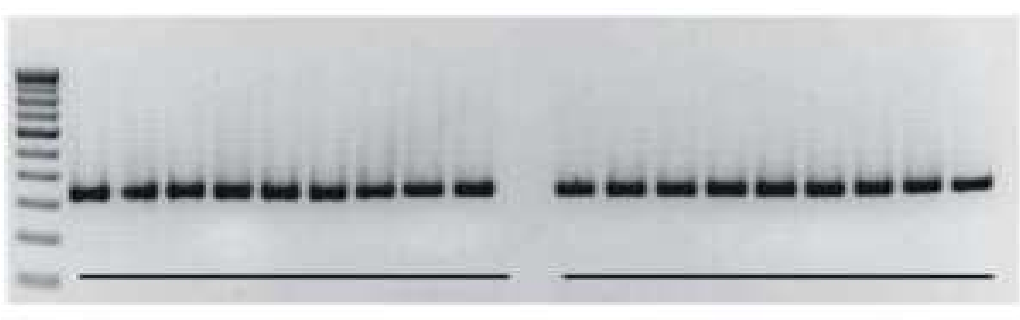

IR 58025 A

IR 58025 B

(A)

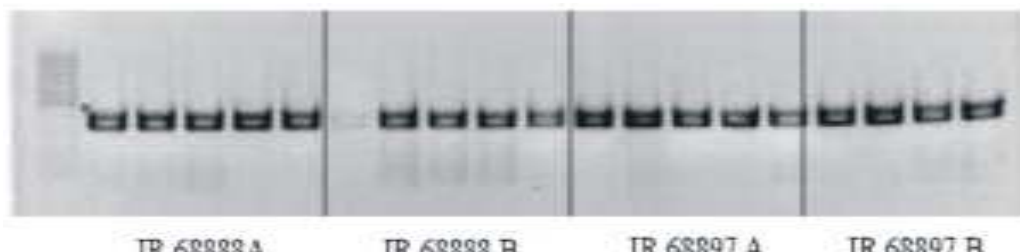

(B)

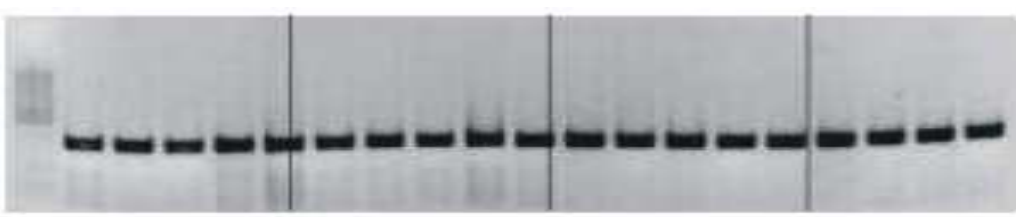

IR 79128 A

IR $79128 \mathrm{~B}$

C)

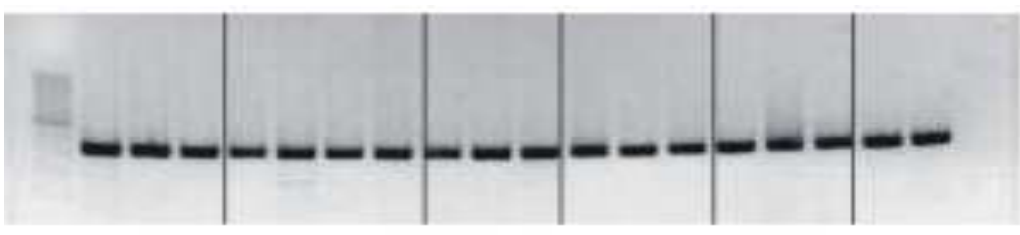

R1 R2 R3

(D)

Fig. 5. Amplification profile of rice genotypes: CMS lines and their cognate maintainers, restorer lines, with BF-STS-402 primers 


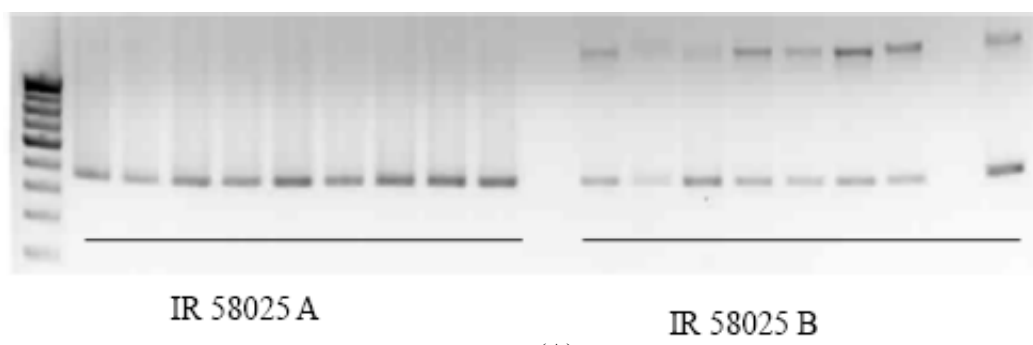

(A)
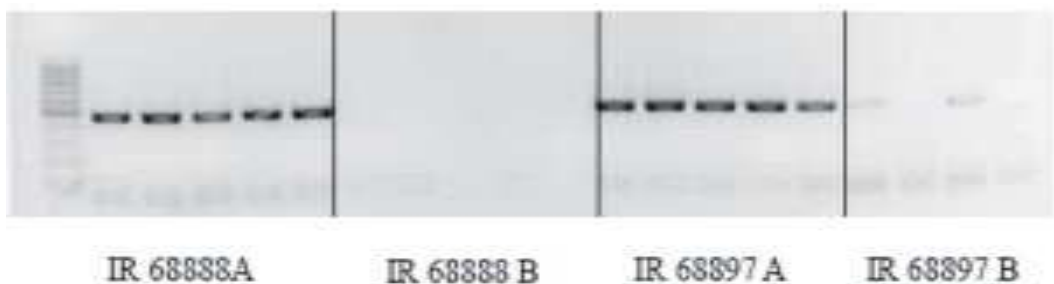

$\mathbb{R} 68888$ B

IR 68897 A IR 68897 B

(B)
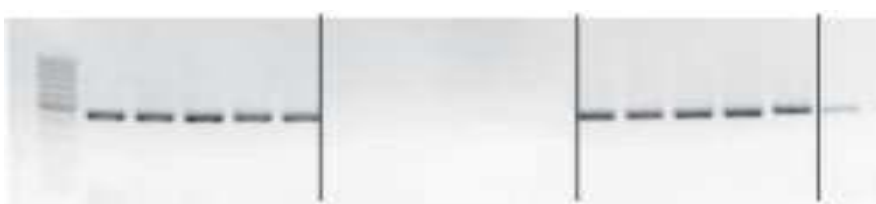

IR $79128 \mathrm{~A}$

IR. $79128 \mathrm{~B}$

$\operatorname{IR} 79156 \mathrm{~A}$

IR 79156 B

(C)
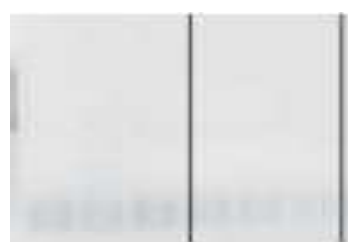

RI

R2
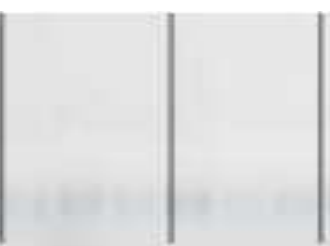

R3

R4

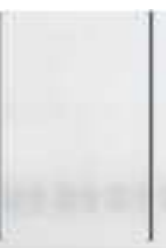

R5

(D)

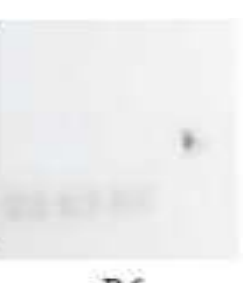

R6

Fig. 6. Amplification profile of rice genotypes: CMS lines and their cognate maintainers, restorer lines, with BF-STS-401 primers

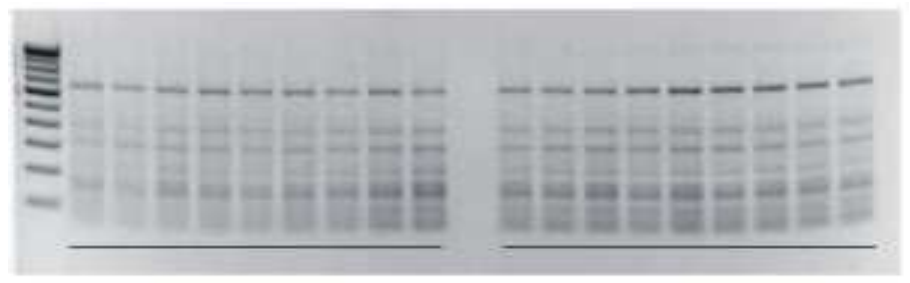

IR 59025 A

IR 58025 B

(A)

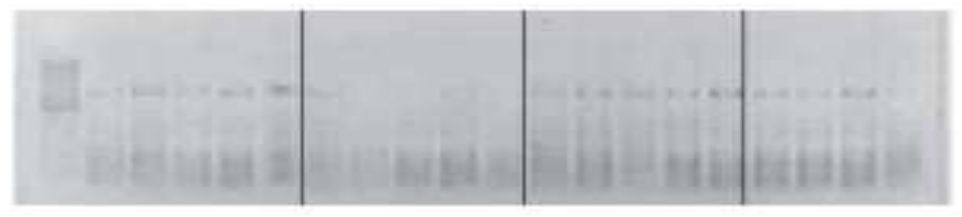

IR 68888A IR 68888 B IR 68897 A IR 68897 B

(B) 


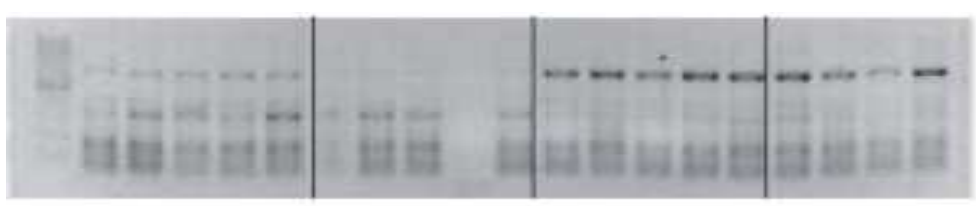
IR $79128 \mathrm{~A}$
IR 79128 B
IR 79156 A
IR 79156 B
(C)

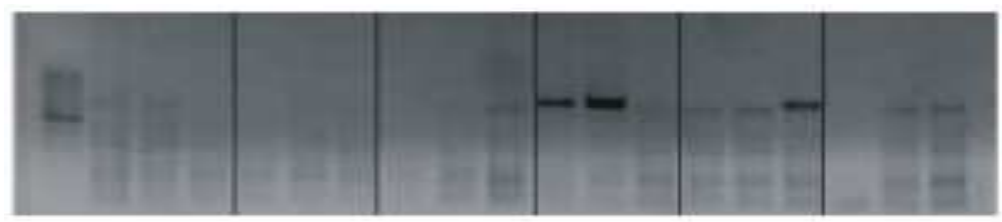

$\begin{array}{llllll}\mathrm{R} 1 & \mathrm{R} 2 & \mathrm{R} 3 & \mathrm{R} 4 & \mathrm{R} 5 & \mathrm{R} 6\end{array}$

Fig. 7. Amplification profile of rice genotypes: CMS lines and their cognate maintainers, restorer lines, with pTA 248 primers

$\begin{array}{llllll}\text { IR } 58025 & \text { IR } 68888 & \text { IR } 68897 & \text { IR } 79128 & \text { IR } 79156\end{array}$

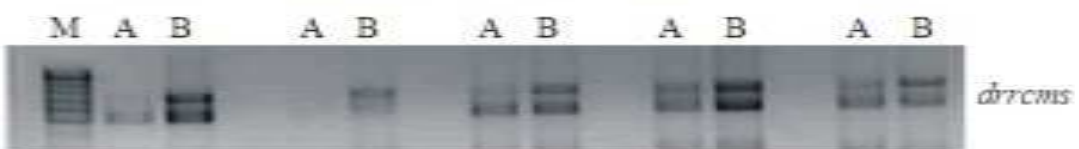

(A)

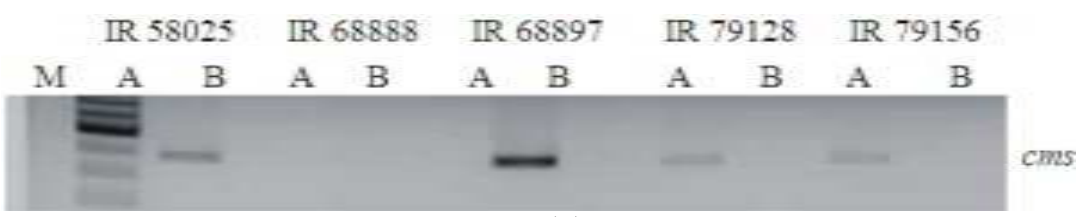

(B)

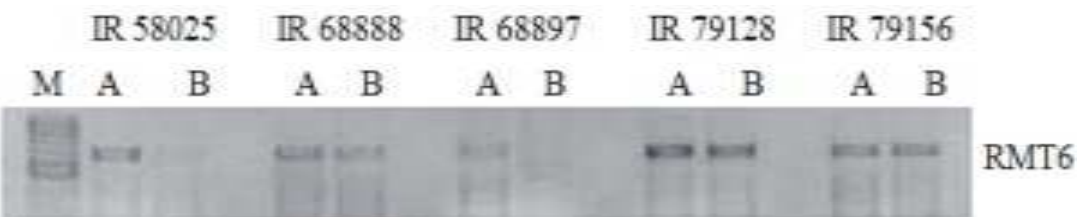

(C)

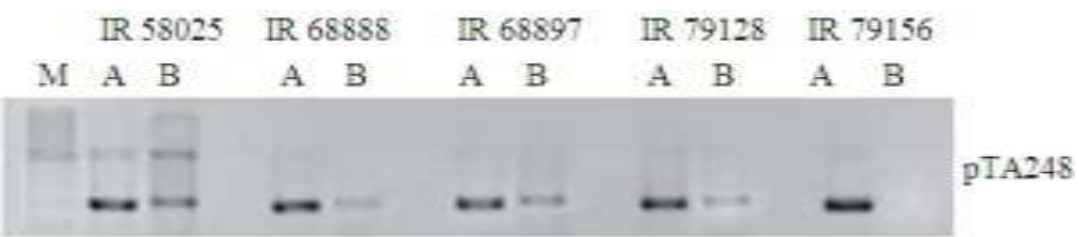

(D)

Fig. 8. Validation in five diverse CMS lines having WA sterility along with their maintainers with different known primers

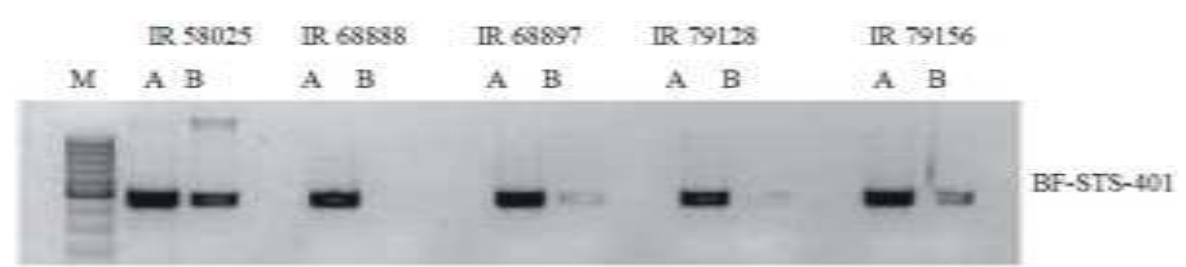

(A) 


\begin{tabular}{|c|c|c|c|c|c|c|}
\hline \multirow[b]{2}{*}{ M } & $\mathbb{R} 58025$ & IF 58858 & R.68897 & $\mathbb{R} 7912$ & $\mathbb{R} 73156$ & \\
\hline & $A B$ & $A \quad B$ & $A B$ & A $B$ & A $B$ & \\
\hline & $=$ & $1=1$ & $=1$ & $=1$ & tat & BE-STS- 402 \\
\hline
\end{tabular}

(B)

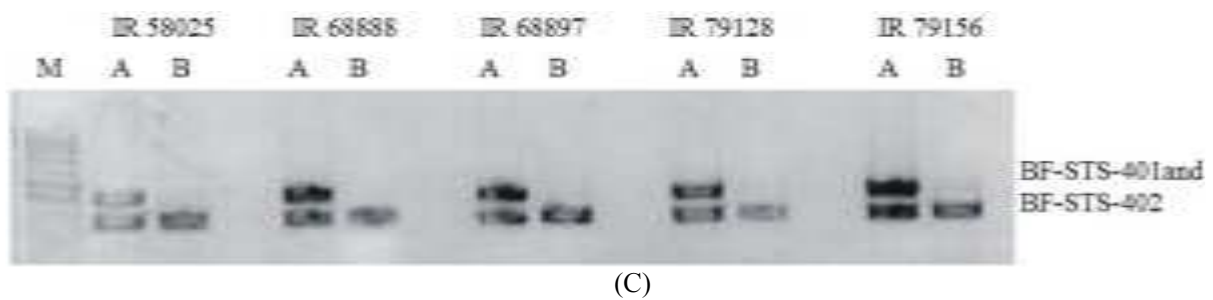

Fig. 9. Validation in five diverse CMS lines having WA sterility along with their maintainers with different known primers

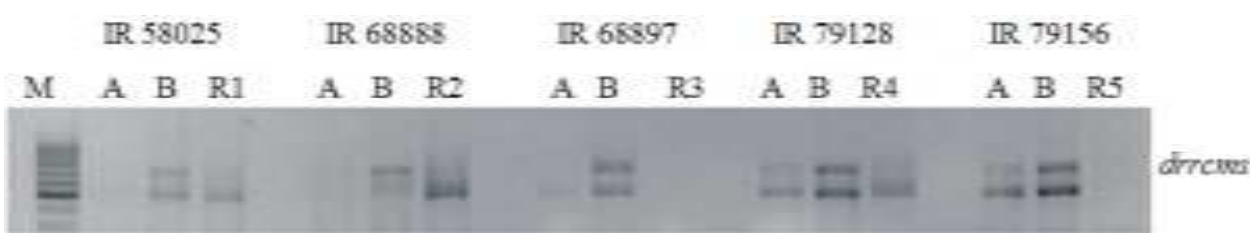

(A)

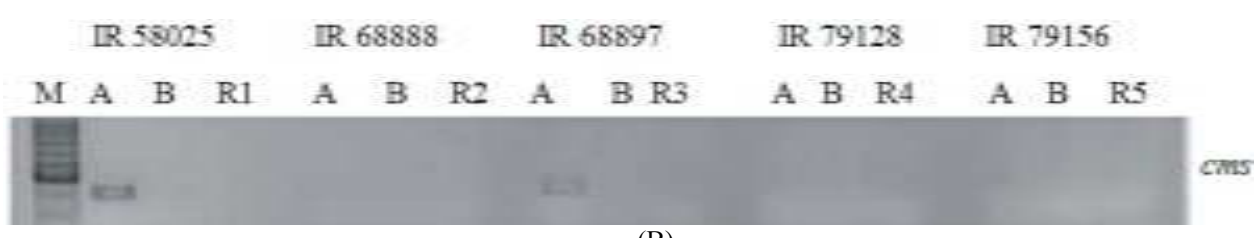

(B)

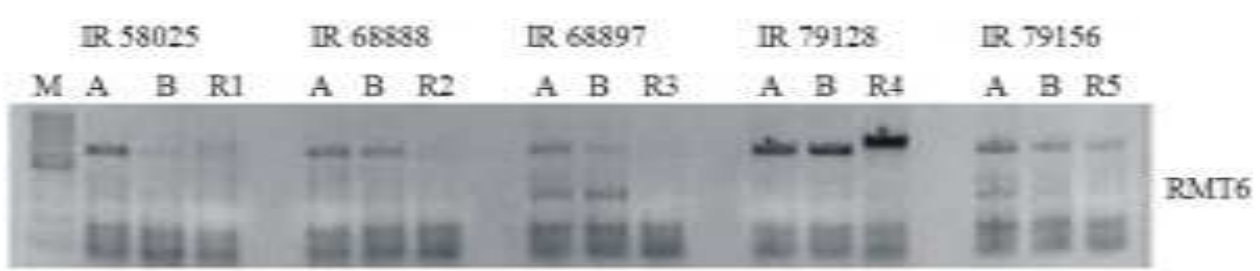

(C)

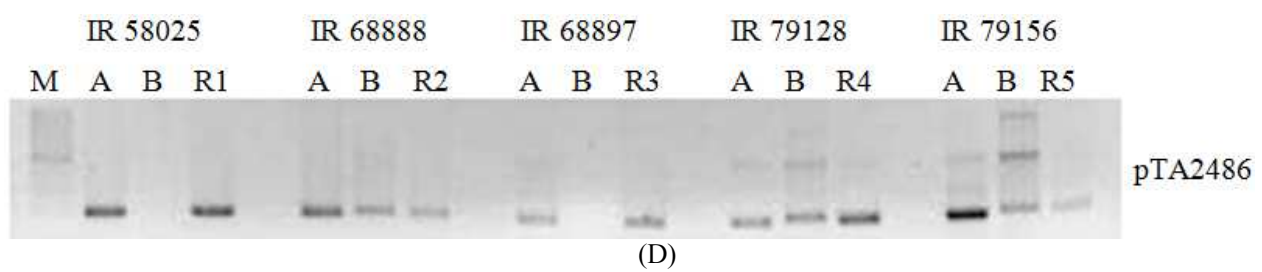

Fig. 10. Validation in five diverse CMS lines having WA sterility along with their maintainers as well as restorers with different known primers

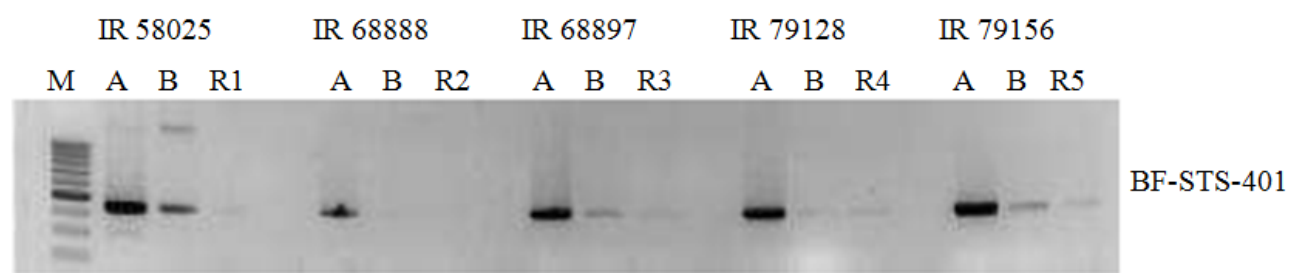

(A) 


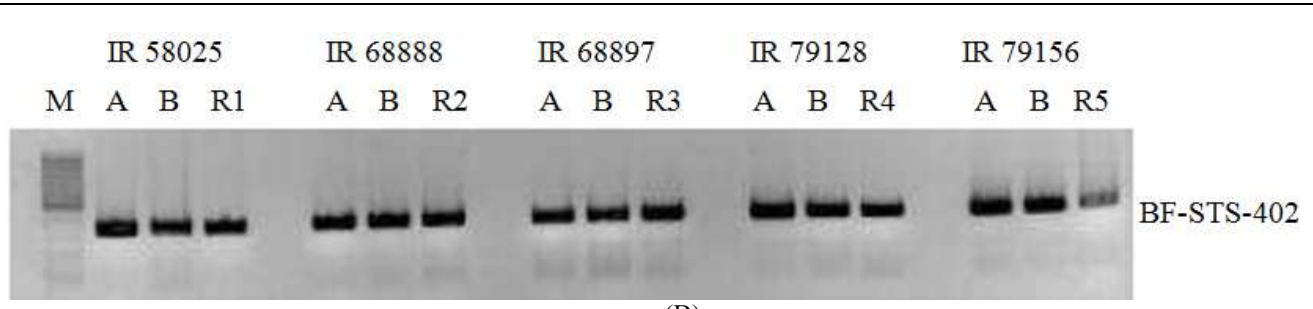

(B)

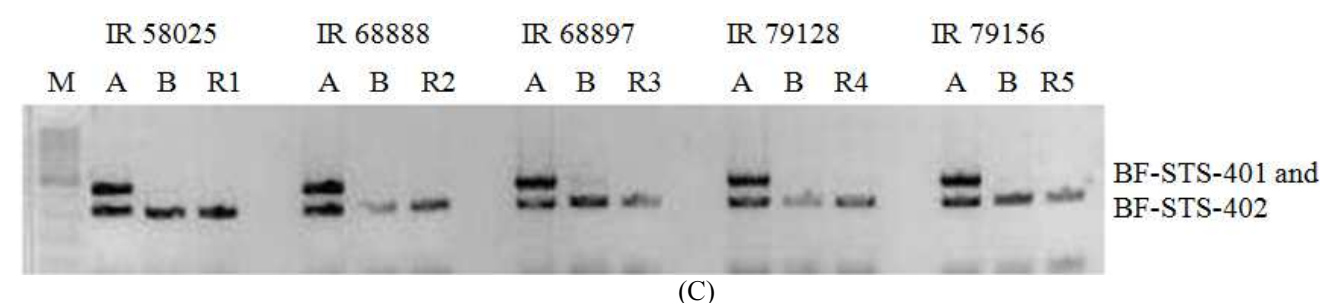

Fig. 11. Validation in five diverse CMS lines having WA sterility along with their maintainers as well as restorers with different known primers

Amplification Pattern Generated by PTA 248 Primer Pair

pTA 2486 generated multiple bands in both CMS and their cognate maintainer lines. Such banding pattern was almost uniform for all five sets of CMS line pairs (Fig. 7 A-C). Further, this primer pair could not differentiate the restorer lines from CMS/maintainer lines as similar multiple lines were generated in all test lines (Fig. 7 D).

\section{Comparison of Different CMS, Maintainers and Restorer Lines}

Comparisons in the banding profile were also studied in CMS lines of 5 different WA cytoplasmic origins for their amplification profile with our tested primers. Additionally, banding profile of all maintainers as well as restorers was also done (Figs. 8-11).

All these five CMS lines have different origins of WA cytoplasm; therefore they have different banding patterns with primers. Only IR 58025 A and B could be differentiated with drrcms primer. A and B lines IR 68888 did not amplify clear bands. A and B lines of IR 68897,79128 and 79156 are indistinguishable from each other (Fig. 8 A).Only A lines of IR 580258 and 68897 could amplify bands thereby distinguishing them from their B counterparts by $\mathrm{cms}$ primer. These bands were completely absent in B lines. A lines of IR 68888, 79128 and 79156 failed to amplify this band (Fig. 8 B). RMT 6 and pTA 248 amplified multiple bands in all lines, thereby making it difficult to differentiate the lines (Fig. $8 \mathrm{C}$ and D).

BF-STS-401 amplified a band of $469 \mathrm{bp}$ in A lines all 5 which was completely absent in B lines of all expect that of IR 58025. In this case additional a band of $1300 \mathrm{bp}$ was also present (Fig. 9 A). BF-STS-402 amplified a band of same size uniformly in all lines, thus making it difficult to discriminate them (Fig. 9 B). However, when BF-STS-401 was multiplex with BF-STS-402, a very clear cut difference was recorded between $\mathrm{A}$ and $\mathrm{B}$ lines in all 5 cases (Fig. 9 C). When the banding patterns of restorers were combined with $\mathrm{A}$ and $\mathrm{B}$ lines a very much similar patterns to that of $B$ line were recorded in cases. At most of the times, restorer lines behaved like the B lines (Figs. 10 and 11).

\section{Conclusion}

All five CMS lines used in the present study were having the origin of WA cytoplasm. The line IR 25A and its cognate maintainer IR $25 \mathrm{~B}$ are the most uniform out of all the other four CMS lines and their maintainers. The amplification profile was comparable for all the primer pairs used for IR $25 \mathrm{~A}$ and IR $25 \mathrm{~B}$, as reported in the literature. Most of the commercial hybrids are based on IR 25 A and IR 25 B lines only, the reason behind this could be a high degree of uniformity among individuals to other CMS lines. Primers drrcms, cms and BF-STS-401 could be successful used for analyses of the genetic purity of various lines. Different restorer lines behaved like B lines in their amplification profiles. BF-STS-401 when multiplexed with BF-STS-402 was most suitable for discriminating CMS lines of all 5 origins. A and B lines of IR 58025 and IR 68897 could be identified by $\mathrm{cms}$ primers, while drrcms could do so only for IR 58025 .

\section{Acknowledgment}

This work was supported by the Barwale Foundation, Hyderabad, India. We thank Mr. Dinesh C. Joshi, Executive Director and Dr. Vinay Shenoy, Director Research for his support and encouragement. 


\section{Author's Contributions}

Sunil Bhavsar: Participated in all experiments, Coordinated the data analysis and writing of the manuscript.

Twinkle Solanki: Participated in all experiments and

Contributed in writing of the manuscript.

Suchita Amin: Participated in all experiments and Coordinated in data analysis.

Neeru Jain: This work was conceived, planned and co-ordinated.

\section{Ethics}

The authors declare that there is no conflict of interests regarding the publication of this paper.

\section{References}

Dellaporta, S.L., J. Wood and Hicks, J.B., 1983. A Plant DNA minipreparation: Version II. Plant Mol. Biol. Rep., 1: 19-21. DOI: 10.1007/BF02712670

Gallagher, L.J., S.K. Betz and C.D. Chase, 2002. Mitochondrial RNA editing truncates a chimeric open reading frame associated with $\mathrm{S}$ malesterility in maize. Curr. Genet., 42: 179-184.

DOI: $10.1007 / \mathrm{s} 00294-002-0344-5$

Jirong, T., 2000. Talents in China. Hunan Agric. Sci. Technol. News., 1: 2-2.

Khush, G.S., 2005. What it will take to feed 5.0 billion rice consumers in 2030. Plant Mol. Biol., 59: 1-6. DOI: $10.1007 / \mathrm{s} 11103-005-2159-5$

Mao, C.X., S.S. Virmani and I. Kumar, 1996. Technological Innovations to Lower the Costs of Hybrid Rice Seed Production. In: Advances in Hybrid Rice Technology, Virmani, S.S. and K. Muralidharan (Eds.), Directorate of Rice Research, Hyderabad, India, ISBN: 971-22-011-55.pp: 111-128.

Nandakumar, N., A.K. Singh, R.K. Sharma, T. Mohapatra and K.V. Prabhu et al., 2004. Molecular fingerprinting of hybrids and assessment of genetic purity of hybrid seeds in rice using microsatellite markers. Euphytica, 136: 257-264.

DOI: 10.1023/B:EUPH.0000032706.92360.c6

Rajendrakumar, P., A.K. Biswal, S.M. Balachandran, M.S. Ramesha and B.C. Viraktamath et al., 2007. A mitochondrial repeat specific marker for distinguishing wild abortive type cytoplasmic male sterile rice lines from their cognate isogenic maintainer lines. Crop Sci., 47: 207-211. DOI:10.2135/cropsci2006.06.0365

Rajendran, N., G. Ramkumar, S. Singh and K. Palchamy, 2007. Development of a DNA marker for distinguishing CMS lines from fertile lines in rice (Oryza sativa L.). Euphytica, 156: 129-139.

DOI: 10.1007/s10681-007-9360-3
Satoh, M., T. Kubo, S. Nishizawa, A. Estiati and N. Itchoda et al., 2004. The cytoplasmic male-sterile type and normal type mitochondrial genomes of sugar beet share the same complement of genes of known function but differ in the content of expressed ORFs. Mol Genet Genomics 272: 247-256. DOI: $10.1007 / \mathrm{s} 00438-004-1058-9$

Sindhu, J.S. and I. Kumar, 2002. Quality seed production in hybrid rice. Proceedings of the 20th Session of International Rice Commission, (IRC' 02), Bangkok, Thailand.

Virmani, S.S. and C. Shinjyo, 1988. Current status of analysis and symbols for male-sterile cytoplasms and fertility-restoring genes. Rice Genet. Newsl., 5: 9-15.

Virmani, S.S., 1996. Hybrid rice. Adv. Agron., 57: 377-462. DOI: 10.1016/S0065-2113(08)60928-1

Wang, Z., Y. Zou, X. Li, Q. Zhang and L. Chen et al., 2006. Cytoplasmic male sterility of rice with boro II cytoplasm is caused by a cytotoxic peptide and is restored by two related PPR motif genes via distinct modes of mRNA silencing. Plant Cell, 18: 676-687. DOI: $10.1105 /$ tpc. 105.038240

Yamamoto, M.P., T. Kubo and T. Mikami, 2005. The 5'leader sequence of sugar beet mitochondrial atp6 encodes a novel polypeptide that is characteristic of Owen cytoplasmic male sterility. Mol. Genet. Genomics, 273: 342-349. DOI: $10.1007 / \mathrm{s} 00438-005-1140-\mathrm{y}$

Yashitola, J., R.M. Sundaram, S.K. Biradar, T. Thirumurugan and M.R. Vishnupriya et al., 2004. A sequence specific PCR marker for distinguishing rice lines on the basis of Wild Abortive cytoplasm from their cognate maintainer lines. Crop Sci., 44: 920-924. DOI:10.2135/cropsci2004.9200

Yashitola, J., T. Thirumurugan, R.M. Sundaram, M.K. Naseerullah and M.S. Ramesha et al., 2002. Assessment of purity of rice hybrids using microsatellite and STS markers. Crop Sci., 42: 1369-1373. DOI: 10.2135/cropsci2002.1369

Yuan, L.P., 1995. Current Status of Hybrid Rice in China and Future Strategies for 21 st Century. In: Hybrid Rice Seed Production Technology, Ahmed, M.I. and B.C., Viraktamath (Eds.), Directorate of Rice Research, Hyderabad, India, pp: 31-33. 